\title{
The impact ofseasonal regulation of metabolism on the life history of Antarctic krill
}

\author{
Dominik Bahlburg ${ }^{\mathrm{a}, \mathrm{b}, *}$, Bettina Meyer ${ }^{\mathrm{c}, \mathrm{d}, \mathrm{e}}$, Uta Berger ${ }^{\mathrm{a}}$ \\ ${ }^{\text {a }}$ Technical University Dresden, Forest Biometrics and Forest Systems Analysis, Pienner Straße 8, D-01737 Tharandt \\ ${ }^{\mathrm{b}}$ Helmholtz Centre for Environmental Research Leipzig/Halle, Department of Ecological Modelling, Permoserstraße 15, D-04318 Leipzig \\ ${ }^{c}$ Alfred Wegener Institute Helmholtz Centre for Polar and Marine Research, Section Polar Biological Oceanography, Am Handelshafen 12, D-27570 Bremerhaven \\ ${ }^{\mathrm{d}}$ Institute for Chemistry and Biology of the Marine Environment (ICBM) Carl-von-Ossietzky University, Carl-von-Ossietzky-Straße 9-11, D-26111 Oldenburg \\ ${ }^{\mathrm{e}}$ Helmholtz Institute for Marine Functional Biodiversity (HIFMB), Ammerländer Heerstrasse 231, D-26111 Oldenburg
}

\section{A R T I C L E I N F O}

\section{Keywords:}

DEB theory

Euphausia superba

Metabolic regulation

Temperature

Photoperiod

\begin{abstract}
A B S T R A T
Antarctic krill up- and down-regulate their metabolism as a strategy to cope with the strong seasonal environmental fluctuations in the Southern Ocean. In this study, we investigate the impact of this light- and temperature dependent metabolic regulation on growth, reproduction and winter survival of krill. Therefore, we advance a bioenergetic growth model of krill by adding a data-derived scaling function of krill activity. With SERBIK (SEasonally Regulated BIoenergetic Krill growth model), we conduct a numerical experiment which tests the impact of such scaling on krill life history under two different winter food conditions: In the first scenario, we simulate life history of krill when winter food availability is low; in the second scenario, winter food availability is increased within realistic ranges. The results demonstrate that the scaling of metabolism is especially important during low food winters. Reducing metabolism during winter permits individuals to grow to larger body length, reproduce successfully and release a greater number of eggs. It further significantly reduces withinyear size fluctuations caused by starvation during months with low food availability. Finally, SERBIK can be used in future spatial modelling studies which include movement of krill along latitudinal gradients and thus spatiotemporal gradients in light- and temperature.
\end{abstract}

\section{Introduction}

Antarctic krill (Euphausia superba, Dana, 1852 - hereafter krill) is considered a key species in the Southern Ocean ecosystem. Its enormous biomass and circumpolar distribution makes krill an important organism in the functioning of nutrient cycling, carbon export and trophic interactions in the Southern Ocean (Le Fèvre et al. 1998, Ballerini et al. 2014, Belcher et al. 2017). This central role, a rapidly changing environment (Gille 2002, Whitehouse et al. 2008) and the growing krill fisheries industry put pressure on the scientific community to improve the understanding of krill as individuals, populations and as part of a complex network of biogeochemical processes. In this context, it is necessary to go beyond phenomenological descriptions of the response of krill to environmental cues but explore and understand the underlying bio-physical processes mechanistically.

The response of krill to the physical environment is closely linked to its relatively complex life cycle. After hatching, krill goes through 12 larval stages until it reaches sexual maturity after approximately 2-3 years (Ikeda 1984; Ikeda 1987; Jia et al. 2014; Quetin et al. 1994). During this time, individuals undergo significant changes in their body shape (from rather compact nauplius larvae to elongated furciliae, juveniles and adults), feeding behaviour (yolk reserves or active feeding), their ability to store lipids and sexual maturation. The dynamics of these life-history traits are directly affected by the strong seasonal fluctuations in food and light availability, temperatures and sea ice.

Krill population, and thus biomass dynamics emerge from the interplay of many individual life histories. Therefore, a comprehensive mechanistic understanding of individuals' life histories could open new doors for many theoretical and applied krill studies. However, the dependence of individual krill life history on specific environmental drivers remains unclear. The Southern Ocean is a habitat characterized by strong seasonal fluctuations of light, temperature, food availability and sea ice extend. In order to survive in such an extreme environment, krill needs to find ways to cope with these strong fluctuations. The

\footnotetext{
* Corresponding author.

E-mail address: dominik.bahlburg@tu-dresden.de (D. Bahlburg).
} 
resulting eco-physiological adaptations of the crustaceans are expressed as internal regulation of metabolism, adaptive behaviours or other strategies such as shrinkage. These adaptations, in turn, affect the dynamics of reproduction, growth and starvation which are commonly referred to as the "life history" of an individual. In this study, we focus on the seasonal scaling of krill metabolism as a particularly important adaptation to the strong seasonality in temperature and light availability of the Southern Ocean. Seasonal scaling of metabolism describes the upand down-regulation of an individual's metabolic activity which is mainly driven by light and temperature.

Therefore, we advance an existing bioenergetic model which describes the growth of individual krill based on the Dynamic Energy Budget theory (DEB, Jager and Ravagnan 2015). This theory describes the development of an individual as a function of energy intake and its subsequent allocation into reproduction and growth (Kooijman 2010). It has been successfully applied to a broad range of organisms such as Icelandic capelins (Einarsson et al. 2011), the Pacific oyster (Ren and Ross 2001) and even endoparasitic wasps (Llandres et al. 2015). Recent studies (Guillaumot et al. 2020; Groeneveld et al. 2020) emphasize how individual based modelling and DEB-theory can be especially useful for studying Antarctic species when habitat access is limited and data is sparse. The framework of bioenergetic modelling further holds the potential to project from individuals to population dynamics, which makes the development of a DEB-based krill model particularly interesting (Martin et al. 2013). The full theoretical background of DEB theory is described in Kooijman (2010) and a summary can be found in Jager et al. (2013). Parameterizing a DEB-based growth model, however, requires detailed knowledge about the ecophysiology of krill. Jager and Ravagnan (2015) propose a first version of such a model and demonstrate its general applicability to reproduce typical life history patterns. Nevertheless, it most notably lacks a seasonal component which scales krill metabolism under the influence of environmental drivers. In addition, the Jager and Ravagnan (2015) model has only been tested under "laboratory" conditions with ad libitum food availability and constant water temperatures of $0{ }^{\circ} \mathrm{C}$. The study presented is intended to overcome this lack of knowledge by (1) including environmental seasonality and thus, seasonality in the krill's metabolism, and (2) parameterizing and validating the model against field data.

Another feature of the model proposed by Jager and Ravagnan (2015) is that the individual is running at "full blast" throughout its life. All physiological functions such as feeding and metabolism are constantly running at their maximum physiological rates. However, past and current research shows that the metabolism of krill undergoes strong seasonal oscillations with increased metabolic rates (measured as weight-specific oxygen consumption rates) during the Austral summer and reduced rates during winter (Brown et al. 2013; Kawaguchi et al. 1986; Meyer et al. 2010). During winter, mean respiration rates can correspond to only $29 \%$ of summer rates (Meyer et al. 2010). Meyer et al. (2010) and Atkinson et al. (2002) show that a similar scaling happens with winter feeding rates which can also be as low as $20 \%$ of summer rates when individuals are exposed to similar feeding conditions. These findings have been backed by long-term experimental studies which investigate annual metabolic dynamics under controlled laboratory conditions (Brown et al. 2013; Piccolin et al. 2018b). While it is clear that there is a strong seasonality in krill activity, the question of possible drivers has not yet been fully answered. More specifically, there is an ongoing debate about how much external factors (temperature, light availability, food concentration) or internal processes (e.g. molecular clocks) contribute to the annual up- and down-regulation of metabolism, respectively. Since there is evidence for both (Biscontin et al. 2017; Brown et al. 2010; Brown et al. 2013; Höring et al. 2018; S. Kawaguchi et al. 2007; Piccolin et al. 2018a; Piccolin et al. 2018b; Teschke et al. 2007), it is likely that a combination of external and internal processes regulate the activity of krill. In general, food, temperature and more recently light availability are often named as main drivers in the seasonal scaling of metabolism.
Temperature dependent scaling of metabolism is one of the key elements of metabolic theory of ecology (Clarke 2006) and annual temperature fluctuations should be reflected in the metabolic activity of krill. The exact functional relationship between krill metabolism and temperature has been subject to numerous studies (Hirche 1984, McWhinnie and Marciniak 1964, Ngan et al. 1997, Segawa et al. 1979, Tarling 2020). In summary, krill metabolism typically seems to follow the Van't Hoff-Arrhenius equation which projects exponentially increasing metabolic costs with increasing temperature. Single studies such as McWhinnie and Marciniak (1964) and Ngan et al. (1997) report saturating metabolic rates above a critical temperature of $\sim 5^{\circ} \mathrm{C}$ and Segawa et al. (1979) observed constant metabolic temperature between $-1^{\circ} \mathrm{C}$ and $3^{\circ} \mathrm{C}$. However, using a much larger dataset, Tarling (2020) found that the Van't Hoff-Arrhenius equation is adequate in describing the thermal response of krill metabolism. Typical Q10-values, which estimate the rate at which metabolism increases with a temperature increase of $10^{\circ} \mathrm{C}$, were found to be $\sim 2.8$. In addition, Tarling (2020) demonstrates that the response is generally independent of geographical location.

The photoperiod - or light exposure - has been linked to respiration rate either as a direct driver (Piccolin et al. 2018b; Teschke et al. 2007) or as a pacemaker which regulates the synchronicity of an endogenous regulation system (Brown et al. 2013, Höring et al. 2018). Similar to temperature, there are strong indications that metabolic rates increase with increasing light exposure of the individual. For instance, Teschke et al. (2007) simulated winter and summer light regimes of the Southern Ocean in order to investigate the physiological response of krill to differences in light exposure. They could observe that winter food assimilation rates could be as low as $36 \%$ of summer rates. Oxygen consumption was significantly lower when individuals were kept under complete darkness compared to high and reduced light availability. In addition, Piccolin et al. (2018a, 2018b) and Höring et al. (2018) demonstrate that light availability alone can drive seasonal patterns of respiration rates or gene expression. Furthermore, Seear et al. (2012) found that winter genes related to feeding activity, digestion and immunity were expressed at higher rates around South Georgia compared to the Antarctic Peninsula. Since winter light availability varies markedly between these two locations, it is possible that light has a role in regulating the expression of these genes. However, the authors could not find differences in the expression of genes involved in respiration.

In this study, we synthesize the new insights from the growing amount of data on seasonal scaling of krill metabolism to parameterize a temperature- and light dependent scaling function. This scaling function is then implemented into the bioenergetic growth model for krill introduced by Jager and Ravagnan (2015). We refer to the new model as SEasonally Regulated BIoenergetic Krill growth model (SERBIK).

With the introduction of SERBIK, we aim to answer two main questions:

1 How does the previous model version compare with a model version where metabolism is scaled as a function of temperature and light availability?

2 How does the seasonal scaling of metabolism impact the life history of krill individuals under different environmental conditions?

It has been suggested that the down-regulation of metabolism helps the individuals to reduce energetic demands during winter when food concentrations are low. A possible reason could be a better physiological condition before food availability starts to increase in spring since resources can be saved during the winter period. In order to address question 2, we generate two environmental datasets which are characterized by low and high winter food availability. The environmental data are derived from field measurements from the Palmer Research Station (Anvers Island, $64.77^{\circ} \mathrm{S}, 64.05^{\circ} \mathrm{W}$ ), part of the Palmer Long Term Ecological Research program (Smith et al. 2013). 


\section{Methods}

We use the R Programming Language (R Core Team 2020) for all coding. Data processing and visualization was done with help of the "tidyverse"-environment (Wickham et al. 2019)

SERBIK builds on an existing growth model published by Jager and Ravagnan (2015). Its description follows the Overview, Design and Details protocol suggested by Grimm et al. (2006; 2020).

\subsection{Purpose}

The purpose of the individual-based bioenergetic growth model is to predict the development of krill individuals as a function of water temperature, food availability and day length. A specific goal is the analysis of the importance of light- and temperature dependent regulation of metabolism on the life history of krill. The model is suitable to investigate inter-seasonal dynamics of krill development for a given latitude and allows intra-seasonal comparisons between different krill habitats. Trajectories for growth, stage development, reproductive output as well as starvation and ultimately death throughout the life of a krill individual for given environmental conditions are used to validate the model's performance against empirical data.

\subsection{Entities, state variables, and scales}

The model consists of two entities - environment and the krill individual.

The environment has three state variables: temperature (water temperature in Kelvin), day length (hours between sunrise and sunset) and food concentration (density of chlorophyll a in $\mathrm{mg} \mathrm{m}^{-3}$ named as chla). The krill individual is characterized by four state variables, namely age (days), structural biomass (measured in mg dry weight), reproductive biomass (mg dry weight) and assimilate stored in the egg buffer (mg dry weight). More information about the entities and their state variables can be found in Table 1.

The model simulates 6 years (or 2190 days) of krill development with a timestep of 1 day. The life span of 6 years lies within commonly suggested maximum life span for krill (Nicol 1990). The model has no spatial component.

\subsection{Process Overview and Scheduling}

Update Environmental Conditions: temperature, day length, and food availability will be updated for the respective day.

Check Developmental Stage: the current stage (embryo, juvenile, or adult) will be assigned to the krill individual based on stage-specific classification criteria.

Growth: the daily net growth of the individual is determined based on the amount of assimilated energy. The energy is allocated to structural biomass. Growth can be either positive or negative (shrinkage) in case of energy shortages.

Reproduction: Spawning is triggered by a size-dependent threshold energy-level in the reproduction buffer which has to be reached within the spawning window (October $1^{\text {st }}-$ March $31^{\text {st }}$ ).
Mortality: The individual dies after 6 years.

See section "Submodels" for further details.

\subsection{Design concepts}

\subsubsection{Basic principles}

We use a slightly simplified framework derived from standard DEB theory (Sousa et al. 2010) called "DEBkiss" which was introduced by Jager et al. (2013). While both models share the philosophy of describing life-history of an animal as a function of energy uptake and allocation, DEBkiss most noticeably lacks an intermediate energy storage between energy uptake (feeding) and energy allocation. A simplified scheme of the model is shown in Fig. 1.

\subsubsection{Emergence}

The model produces inter- and intra-annual fluctuations of body size, stage development and energy in the reproduction buffer as a result of a seasonally varying environment (chlorophyll a, light availability, temperature).

In addition, the (de)activation of light- and temperature dependent scaling of metabolism produces varying trajectories of life history,

\subsubsection{Adaptation}

The agents are not capable of adaptation or decision making.

\subsubsection{Sensing}

Individuals are aware of the current month in order to determine whether the current day lies within the reproductive period or not. They are also aware of ambient temperature, day length and food concentration.

\subsubsection{Interaction}

In this study, the model simulates only one individual at a time. Thus, there is no interaction between individuals.

\subsubsection{Stochasticity}

The model is deterministic and includes no stochastic processes.

\subsubsection{Observation}

At each time step, information about age, date, structural body mass, biomass stored in the reproduction buffer and energy stored in the egg buffer are output to a main data table which contains a broad overview about the state of the individual. In a separate table, the model records daily information on the bioenergetics such as energy assimilation, maintenance costs, energy deficits, whether and how much structural biomass has been assimilated and spawning events. Since the complete environmental dataset is generated at the model initialization, there is no need to specifically write out environmental information at each timestep.

\subsection{Initialization}

Per default, the simulation starts on January $1^{\text {st }}$. However, the initialization date can be set to any day of the year.

Table. 1

State variables of the krill growth model and their properties






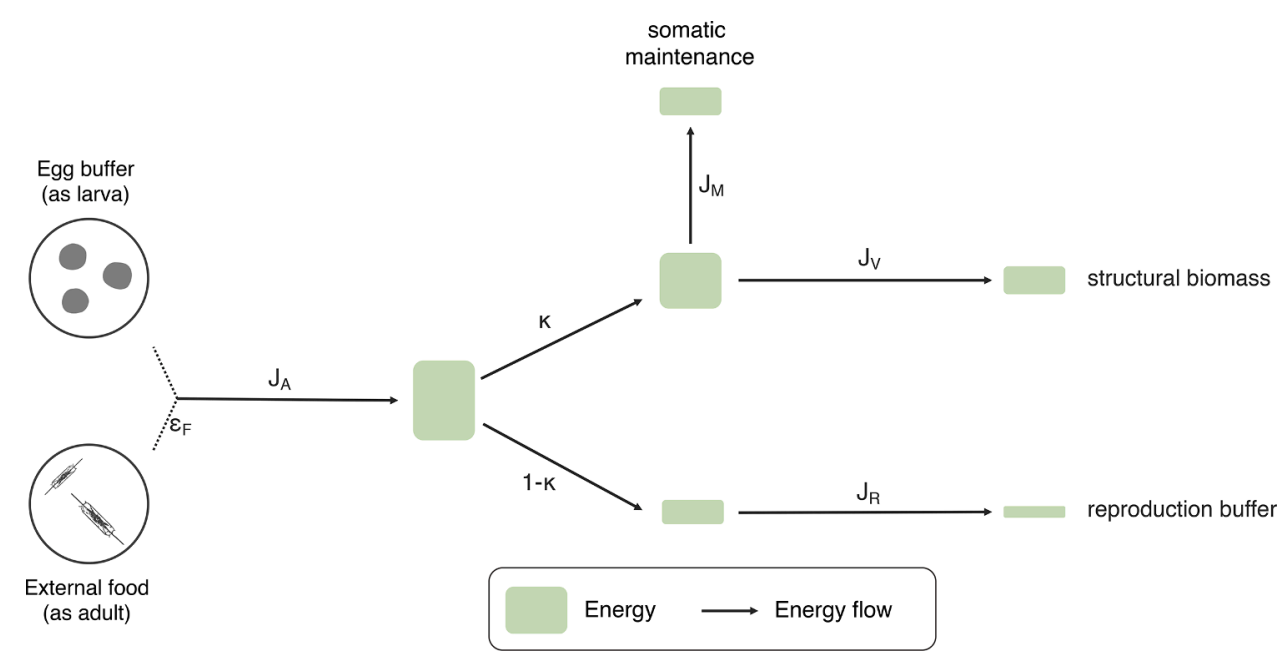

Fig. 1. Schematic depiction of the major compartments of the krill growth model. While in the non-feeding larval state, the individual assimilates energy from the egg buffer. When feeding, the individual ingests energy which is converted into assimilates at the rate $\varepsilon_{\mathrm{F}}$. The assimilated energy, $\mathrm{J}_{\mathrm{A}}$, is then allocated to

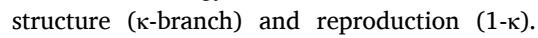
Energy from the $\kappa$-branch is partially depleted as maintenance costs of structure $\left(\mathrm{J}_{\mathrm{M}}\right)$ while the remainder, $\mathrm{J}_{\mathrm{v}}$, goes into new structural biomass. Reproduction energy following the 1$\kappa$-branch is allocated to the reproduction buffer. $\mathrm{J}_{\mathrm{R}}$ equals the " $1-\kappa$ - energy" minus some losses due to the conversion of assimilates into reproductive biomass.
After the initialization date and total running time (default: 6 years/ 2190 days) are set, the environmental dataset for the entire simulation is generated starting at the respective initialization date. The user chooses between two environmental scenarios:

1 "palmer" - which represents annual food and temperature dynamics derived from field data from Palmer Research Station

2 "palmer winter boost" - which generates the same data for the summer months as "palmer" but increases food availability during winter, as described in Section 2.6.6

After the environment is generated, the krill individual is initialized with very low but non-zero structural biomass $\left(10^{-4} \mathrm{mg}\right.$ dry weight $)$ and a full egg buffer which equals the assimilates contained within the eggs after spawning ( $0.028 \mathrm{mg}$ dry weight). Before the simulation starts, the user can choose whether light- and temperature dependent scaling of metabolism should be active or not with the default being active.

\subsection{Input Data}

In order to address question 2, we generate two environmental datasets which are characterized by low and high winter food availability. The environmental data are derived from field measurements from the Palmer Research Station (Anvers Island, $64.77^{\circ} \mathrm{S}, 64.05^{\circ} \mathrm{W}$ ), part of the Palmer Long Term Ecological Research program (Smith et al. 2013). The environmental dataset contains daily climatological values of chlorophyll concentration ( $\mathrm{mg} \mathrm{m}^{-3}$ ), water temperature (Kelvin), and day length (hours).

Daily day length (time between sunrise and sunset at Palmer station) is calculated with help of the R-package "suncalc" (Thieurmel and Elmarhraoui 2019). For the chlorophyll concentrations we use a time series ranging from 1991-2018. The "palmer"-scenario consists of the average monthly chlorophyll $a$ concentrations from this time series. The "palmer winter boost" scenario is composed of average chlorophyll concentrations during months where average chla $>1 \mathrm{mg} \mathrm{m}^{-3}$ and maximum observed chlorophyll concentrations for months where average chla $<1 \mathrm{mg} \mathrm{m}^{-3}$. Temperature data are calculated as daily mean surface water temperatures from the same time range.

This way, we create an environmental dataset which spans over 1 year. Since we do not consider interannual variation, the full environmental dataset used in the simulation consists of (six) consecutive repetitions of this annual dataset. The annual environmental dynamics are shown in Fig. 2.

\subsection{Submodels}

\subsubsection{Update Environmental Conditions}

In each timestep, the model extracts water temperature, food concentration and day length from the environmental dataset for the current day. These data are used as input data for the physiological functions defined in the following submodels.

\subsubsection{Check Developmental Stage}

the particular stage (embryo, juvenile, or adult) will be assigned to the krill individual. Consistent with DEB-theory, the individual goes through three developmental stages. Individuals start as embryos (stage 1) which first live off the energy reserves stored in the egg buffer. When the egg buffer is depleted, hatching occurs and the individuals advance into the juvenile stage (stage 2). Juveniles actively feed from the water column and invest energy into somatic growth and the reproduction buffer. However, the energy allocated to reproduction is completely burned which is interpreted as maturation of the gonads. After the
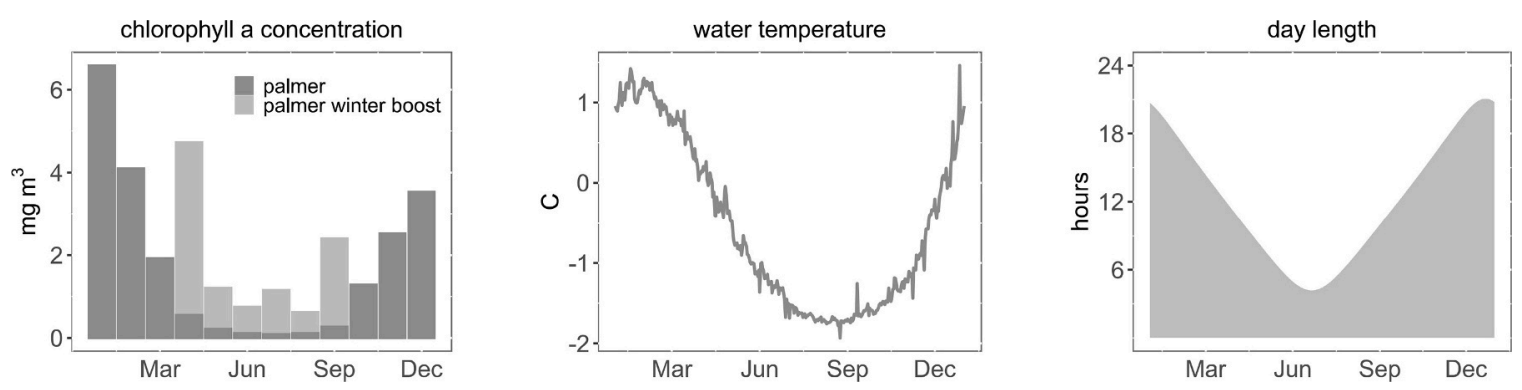

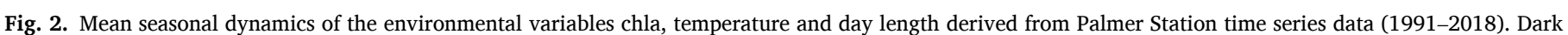

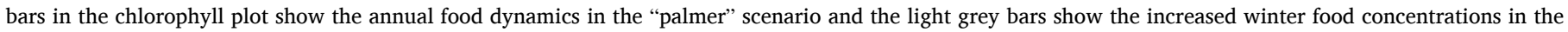
"palmer winter boost" scenario. 
juvenile reaches a critical length of $35 \mathrm{~mm}$, "puberty" is reached and the individual is considered an adult (stage 3, Siegel and Loeb 1994). In contrast to juveniles, adults are able to store assimilates in the reproduction buffer which enables spawning. Only adults can spawn. Based on these criteria (egg buffer depletion, critical length of $35 \mathrm{~mm}$ ), the model assigns the respective developmental stage to the individual. This is necessary since it decides which food source is used and whether assimilates allocated to the reproduction buffer can be stored or not.

\subsubsection{Growth}

Growth in this model is the change of structural biomass $\left(K_{S}\right)$ of krill over time. It is defined as the difference of assimilated food allocated to structural growth ("к-branch") and structural maintenance costs (metabolism). Many growth-related processes scale with the volumetric length, $L$. The volumetric length is part of DEB-theory and is defined as

$L=\sqrt[3]{\frac{K_{S}}{d_{V}}}$

where

$K_{S}$-structural biomass (mg dry weight)

$d_{V}$-dry weight density (mg dry weight $\mathrm{mm}^{-3}$ )

Thus, growth can be written as:

$\frac{d K_{S}}{d t}=\varepsilon_{S}\left(\kappa J_{A}(L)-J_{M}(L)\right)\left(E_{\text {deficit }}=0\right)-E_{\text {deficit }}$

where

$\varepsilon_{S}$-conversion efficiency of assimilates to structural biomass

$\kappa$-fraction allocation to structural biomass

$J_{A}(L)$-total assimilated energy (function)

$J_{M}(L)$-structural maintenance costs (function)

$E_{\text {deficit }}$-Energy deficit

The equation contains a Boolean switch $\left(E_{\text {deficit }}=0\right)$. A Boolean switch is an expression which behaves like a logical operator in programming. It returns 1 when the condition is true (aka $E_{\text {deficit }}$ is 0 ) or 0 otherwise and thus "keeps" or "cancels out" the first part of the equation.

$E_{\text {deficit }}$ itself is defined as:

$E_{\text {deficit }}=\left(\left|\kappa J_{A}(L)+E_{R}-J_{M}(L)\right|>0\right) \cdot\left|\kappa J_{A}(L)+E_{R}-J_{M}(L)\right|$

where

\section{$E_{R}$-energy stored in the reproduction buffer}

The equation contains another Boolean expression. The resulting $E_{\text {deficit }}$ is positive when the assimilated energy and the energy stored in the reproduction buffer fail to cover somatic maintenance costs. Otherwise it equals 0 .

In summary, three "growth scenarios" are possible:

1 Positive growth in case $\kappa J_{A}(L)>J_{M}(L)$

2 No growth in case $\kappa J_{A}(L) \leq J_{M}(L)$ but assimilates in the reproduction buffer can cover the deficit

3 Negative growth in case $\kappa J_{A}(L)<J_{M}(L)$ and assimilates in the reproduction buffer cannot cover the deficit

The assimilation of energy is described by a Holling type II function and is proportional to $L^{2}$ :

$J_{A}(L)=\left\{\begin{array}{c}M_{\text {reg }}\left(l_{D}, T\right) \varepsilon_{F} \cdot 0.28 A_{\max } L^{2}, \quad \text { when stage }=1 \\ M_{\text {reg }}\left(l_{D}, T\right) \varepsilon_{F} \frac{\text { chla }}{\text { chla }+k} A_{\max } L^{2}, \text { else }\end{array}\right.$

with

$M_{\text {reg }}\left(l_{D}, T\right)$-light- and temperature dependent scaling function $\varepsilon_{F}$-conversion efficiency of food to assimilates chla-chlorophyll a concentration in the environment $\left[\mathrm{mg} \mathrm{m}^{-3}\right]$ $k$-half saturation constant for chlorophyll uptake $\left[\mathrm{mg} \mathrm{m}^{-3}\right.$ ] d]

$A_{\max }$-maximum area-specific assimilation rate $\left[\mathrm{mg}\right.$ dry weight $\mathrm{mm}^{-2}$

$L$-volumetric length [mm]

When the individual is still an embryo (stage $=1$ ), energy from the egg buffer is assimilated with the rate 0.28 . The assimilation rate is parameterized such that hatching occurs after $\sim 30$ days. In the juvenile and adult stage, the amount of ingested food depends on the food density chla, volumetric length $L$ and the metabolic scaling function $M_{r e g}\left(l_{D}, T\right)$ described below.

In contrast to food uptake, somatic maintenance $J_{M}(L)$ is proportional to the body volume of the individual $L^{3}$ : This builds on the assumption that cells are three-dimensional structures which need "three dimensional maintenance". Thus:

$J_{M}(L)=M_{r e g}\left(l_{D}, T\right) J_{M \max } L^{3}$

where $J_{\text {Mmax }}$ stands for the maximum volume-dependent somatic maintenance flux. As with food uptake, somatic maintenance is regulated by the seasonal metabolic scaling function $M_{\text {reg }}\left(l_{D}, T\right)$.

The seasonal metabolic scaling function $M_{\text {reg }}\left(l_{D}, T\right)$ :

$M_{\text {reg }}\left(l_{D}, T\right)$ scales structural maintenance costs and feeding activity as a function of water temperature $T$ and day length $l_{D} . M_{\text {reg }}\left(l_{D}, T\right)$ is composed of two independent sub-functions: a temperature dependent scaling function $f_{T}(T)$ and a light dependent scaling function $f_{P P}\left(l_{D}\right)$ :

Temperature-dependent scaling of metabolism is described using the Van't Hoff-Arrhenius equation:

$f_{T}(T)=\frac{A e^{\frac{-E}{\bar{K} T}}}{A e^{\frac{-E}{K \cdot 27.15}}}$

where

A -pre-exponential factor

E-activation energy [eV]

$K$-Boltzmann constant $=8.61710^{-5} \mathrm{eV} \mathrm{K}^{-1}$

$T$-temperature [Kelvin]

This way, temperature-dependent energy demand of an organism is directly linked to the temperature-dependence of enzyme kinetics. We use experimental data from Hirche (1984) in order to estimate the activation energy $E$. The division by $A e^{\frac{-K}{k \cdot 27.15}}$ scales $f_{T}(T)$ such that the physiological functions related to "krill activity" $\left(J_{A}(L)\right.$ and $\left.J_{M}(L)\right)$ return values equal to their original parameterization at $0{ }^{\circ} \mathrm{C}$ since the original model by Jager and Ravagnan (2015) is parameterized for water temperatures of $0{ }^{\circ} \mathrm{C}$. Thus, for higher water temperatures, simulated krill activity will be increased in comparison to its reference value at $0{ }^{\circ} \mathrm{C}$.

The second sub-function, light-dependent scaling of metabolism, is a linear function based on experiments carried out by Piccolin et al. (2018b). In their study, the authors investigate the response of krill respiration rates (a proxy for metabolic rate) when exposed to different light regimes, keeping all other variables constant. We fit a linear regression function to their data in order to derive $f_{P P}\left(l_{D}\right)$ :

$f_{P P}\left(l_{D}\right)=0.035 l_{D}+0.161$

where

$l_{D}$-photoperiod/day length in hours

In order to derive the linear regression, we scaled the experimental data of Piccolin et al (2018b) such that $f_{P P}\left(l_{D}\right)$ predicts 1 (or 100\%) metabolic activity when day length $l_{D}$ is at its maximum $(24 \mathrm{~h}) . l_{D}$ is defined as the time between sunrise and sunset.

By multiplying both subfunctions, we arrive at the temperature- and light dependent metabolic scaling function:

$M_{\text {reg }}\left(l_{D}, T\right)=f_{T}(T) \cdot f_{P P}\left(l_{D}\right)$

The functioning of $M_{\text {reg }}\left(l_{D}, T\right)$ and its impact on the annual energy budget of a krill individual in the "palmer"-scenario is shown in Fig. 3. 

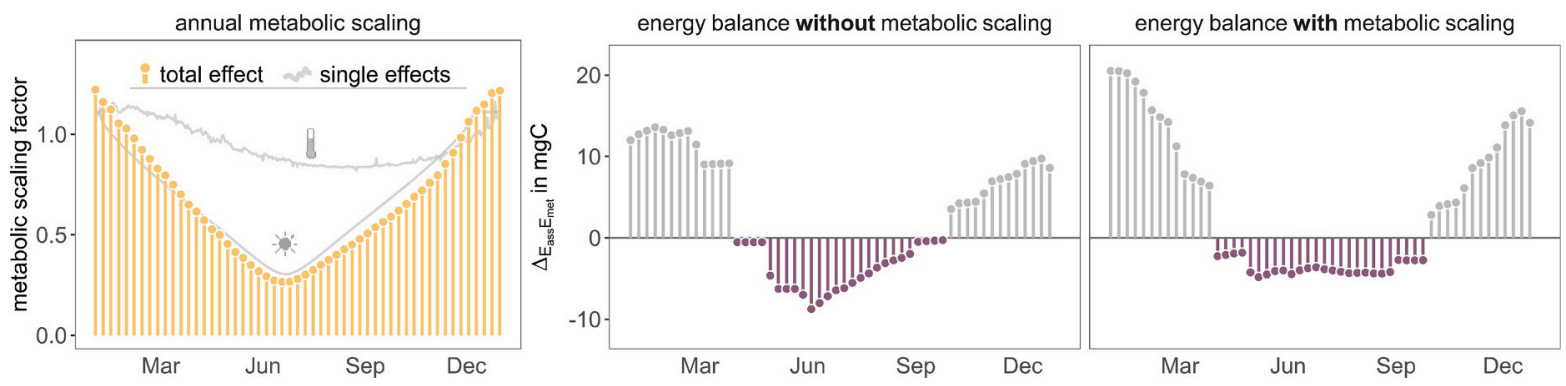

Fig. 3. Left panel: the annual regulation of krill metabolism as a function of light and temperature for environmental conditions measured at Palmer station. Right two panels: Difference between assimilated food and somatic maintenance costs in the last simulation year of the "palmer"-scenario. The lollipops in all three plots show weekly aggregated data.

For the environmental conditions used in this study, $M_{\text {reg }}\left(l_{D}, T\right)$ scales winter krill activity to $32 \%$ of the reference value obtained at $20 \mathrm{~h}$ of daylight and $0{ }^{\circ} \mathrm{C}$ water temperature. During summer, krill activity can increase to $116 \%$ since water temperatures are higher than $0{ }^{\circ} \mathrm{C}$.

\subsubsection{Reproduction}

In this model, reproduction is driven by the amount of assimilates that are stored in the reproduction buffer as well as an annual spawning window that allows for egg release. Energy influx into the reproduction buffer comes from the 1-k-branch when the individual is in the adult stage.

The reproduction buffer serves two purposes:
1 It is the compartment where assimilates are converted into eggs which are released when spawning is triggered.

2 If the ingested food cannot cover structural maintenance costs, energy from the reproduction buffer is allocated to the structure compartment in order to "pay" for the maintenance deficit. Therefore, it can also act as an energy buffer which can be burned under food shortage and prevent the loss of structural biomass.

In general, spawning is triggered when the assimilate dry mass in the reproduction buffer surpasses a size-specific threshold level within the spawning window (October $1^{\text {st }}$-March $31^{\text {st }}$ ). The threshold levelfunction $E_{R e p}\left(L_{B}\right)$ accepts body length $L_{B}$ (in $\mathrm{mm}$ ) as an input variable.

Table. 2

Model parameters and their values. *95\% Confidence interval for estimated parameters obtained via bootstrapping

\begin{tabular}{|c|c|c|c|c|c|}
\hline Type & Abbreviation & Meaning & Value (range) & Unit & Reference \\
\hline \multirow{7}{*}{$\begin{array}{l}\text { Auxiliary } \\
\text { functions }\end{array}$} & $f_{T}(T)$ & temperature-dependent metabolic scaling & $0.3-1.25$ & - & \\
\hline & $f_{P P}(D)$ & light-dependent metabolic scaling & $0.161-1$ & & \\
\hline & $M_{r e g}(l \mathrm{D}, T)$ & environmental scaling of metabolism & $0.46-1$ & & \\
\hline & $J_{A}(L)$ & total assimilated energy & $0-4.66$ & mg dry weight & \\
\hline & $J_{M}(L)$ & structural maintenance costs & $0-2.12$ & mg dry weight & \\
\hline & $E_{\text {deficit }}$ & energy deficit & $0-1.06$ & mg dry weight & \\
\hline & $E_{\text {rep }}$ & reproduction energy threshold & $63-164$ & mg dry weight & \\
\hline \multicolumn{6}{|l|}{ parameters } \\
\hline & \multirow[t]{3}{*}{$E$} & activation energy & $\begin{array}{l}0.663(0.633-0.693) \\
*\end{array}$ & $\mathrm{eV}$ & Hirche 1984 \\
\hline & & slope linear regression light-dependent scaling & $\begin{array}{l}0.036(0.018-0.052) \\
*\end{array}$ & & Piccolin et al. 2018b \\
\hline & & intercept linear regression light-dependent scaling & $0.161(-0.105-0.427)$ & hours & Piccolin et al. 2018b \\
\hline & $\varepsilon_{S}$ & conversion efficiency assimilates to structure & 0.8 & $\mathrm{mgC} \mathrm{mgC}^{-1}$ & $\begin{array}{l}\text { Jager and Ravagnan } \\
\text { (2015) }\end{array}$ \\
\hline & $\kappa$ & fraction allocation to structural biomass & 0.7 & & \\
\hline & $\varepsilon_{F}$ & conversion efficiency food to assimilates & 0.8 & $\begin{array}{l}\text { mg dry weight mg dry } \\
\text { weight }^{-1}\end{array}$ & $\begin{array}{l}\text { Jager and Ravagnan } \\
\text { (2015) }\end{array}$ \\
\hline & $\varepsilon_{\text {metab }}$ & $\begin{array}{l}\text { conversion efficiency structure to cover energy } \\
\text { deficit }\end{array}$ & 0.8 & $\begin{array}{l}\text { mg dry weight mg dry } \\
\text { weight }^{-1}\end{array}$ & $\begin{array}{l}\text { Jager and Ravagnan } \\
\text { (2015) }\end{array}$ \\
\hline & $\varepsilon_{A}$ & conversion efficiency egg buffer to structure & 0.95 & $\begin{array}{l}\text { mg dry weight mg dry } \\
\text { weight }^{-1}\end{array}$ & $\begin{array}{l}\text { Jager and Ravagnan } \\
\text { (2015) }\end{array}$ \\
\hline & $k_{\text {chla }}$ & half saturation constant chlorophyll a uptake & 1 & $\mathrm{mg} \mathrm{m}^{-3}$ & \\
\hline & $A_{\max }$ & maximum area-specific assimilation rate & 0.087 & $\mathrm{mg}$ dry weight $\mathrm{mm}^{-2} \mathrm{~d}^{-1}$ & $\begin{array}{l}\text { Jager and Ravagnan } \\
\text { (2015) }\end{array}$ \\
\hline & $J_{M \max }$ & $\begin{array}{l}\text { maximum volume-specific somatic maintenance } \\
\text { flux }\end{array}$ & 0.0032 & $\mathrm{mg}$ dry weight $\mathrm{mm}^{-3} \mathrm{~d}^{-1}$ & $\begin{array}{l}\text { Jager and Ravagnan } \\
\text { (2015) }\end{array}$ \\
\hline & $w_{e}$ & weight egg & 0.028 & mg dry weight & $\begin{array}{l}\text { Jager and Ravagnan } \\
\text { (2015) }\end{array}$ \\
\hline & $s_{w}$ & spawning window & Oct - Mar & & \\
\hline & $d_{v}$ & dry weight density & 0.22 & $\mathrm{mg}$ dry weight $\mathrm{mm}^{-3}$ & $\begin{array}{l}\text { Jager and Ravagnan } \\
\text { (2015) }\end{array}$ \\
\hline & $c_{B L}$ & conversion factor volumetric length to body length & 5 & & $\begin{array}{l}\text { Jager and Ravagnan } \\
\text { (2015) }\end{array}$ \\
\hline & & transition size juvenile to adult & 35 & $\mathrm{~mm}$ & $\begin{array}{l}\text { Jager and Ravagnan } \\
\text { (2015) }\end{array}$ \\
\hline \multirow[t]{2}{*}{ derived variables } & $L$ & volumetric length & $0.077-9.166$ & $\mathrm{~mm}$ & \\
\hline & $L_{B}$ & body length & $0.34-58.28$ & $\mathrm{~mm}$ & \\
\hline
\end{tabular}


$L_{B}$ refers to the standard length of krill and can be derived from $L$ with help of the shape correction coefficient $\delta_{M}=0.2$ (Jager and Ravagnan, 2015) assuming isomorphy of krill.

$$
E_{R e p}\left(L_{B}\right) \text { is defined as: }
$$

$E_{\text {Rep }}\left(L_{B}\right)=\left(150.83 L_{B}-3027\right) \cdot w_{\text {egg }}$

where $w_{\text {egg }}$ refers to the dry mass of a krill egg (0.028 mg, Table 2). $w_{\text {egg }}$ also equals the weight of assimilates stored in the egg buffer which is depleted by the embryo.

According to this function, small adults $(35 \mathrm{~mm}$ ) will produce $\sim 2250$ eggs and fully grown individuals $(59 \mathrm{~mm}) 5720$ eggs. These values lie within low to intermediate ranges of count data which are summarized in Kawaguchi (2016), slightly higher than clutch sizes in the krill reproduction model of Constable and Kawaguchi (2018) but below those of a reproduction model by Tarling et al. (2007).

\subsubsection{Mortality}

Krill die after they reach an age of 6 years.

\subsection{Model Sensitivity}

We use a parameter screening (Morris method, (Morris 1991) to identify the parameters which have the highest impact on the model dynamics. The screening is performed for three different response variables in the two environmental scenarios ("palmer" and "palmer winter boost"): Maximum body size, day of reaching maturity and the total number of eggs produced.

In conclusion, $A_{\max }, \varepsilon_{F}$ and $\kappa$ turn out to be the most influential parameters in most cases with each being positively correlated to maximum body size and total number of eggs produced. The number of eggs produced is negatively influenced by increases of these parameters meaning that individuals mature earlier at higher parameter values. The detailed sensitivity analysis can be found in the Supplementary Material.

\subsection{Design of numerical experiments}

In order to assess the impact of the light- and temperature dependent

\section{"palmer"}

a)

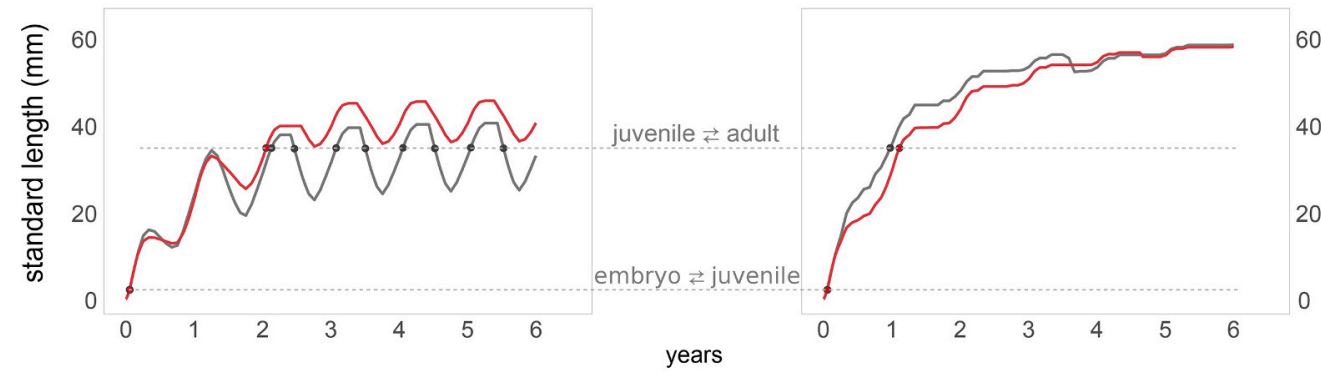

Reproduction buffer

c)

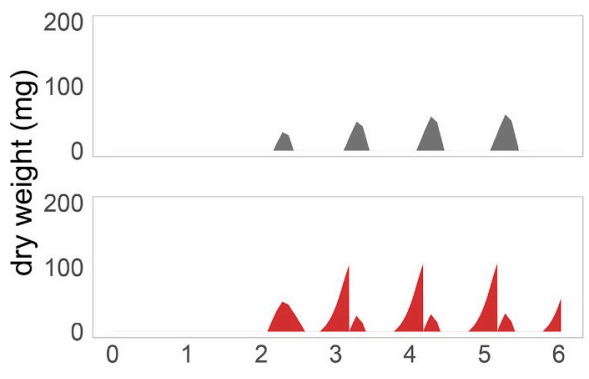

\section{"palmer winter boost"}

Growth b)

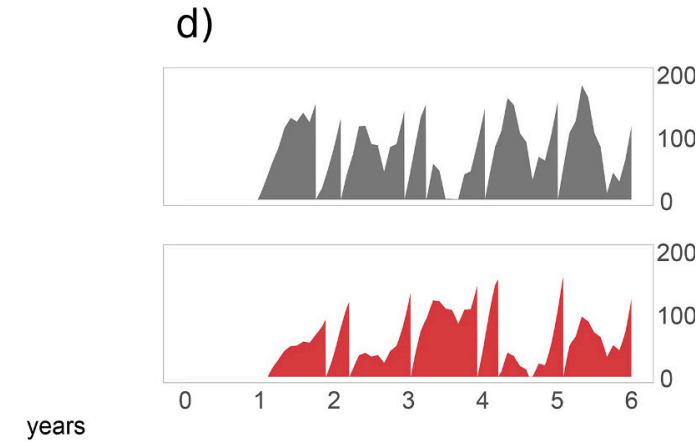

Fig. 4. Results of the simulation experiments: Simulations started on January $1^{\text {st }}$ and ended on December $31^{\text {st }}$ after 6 years. a) and b): Body length of the individual. Dots on the growth curves represent stage transitions of the individual. c) and d): Energy dynamics of the reproduction buffer. e) and f): Spawning events. Each simulation year is represented by one half annulus with time progressing from left to right and from the inside to the outside. Timepoints inside the light grey areas in year 0 and year 7 lie outside the simulated time range.

\section{Timing of spawning events}

e)

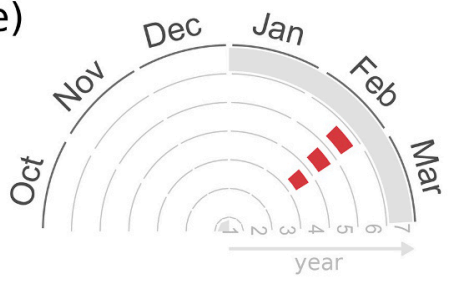

seasonal metabolic scaling turned off f)

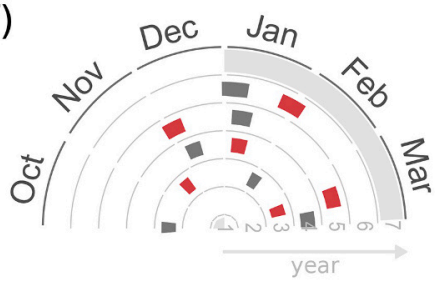

seasonal metabolic scaling turned on 
scaling of krill metabolism, we run the model for two different environmental scenarios as mentioned above, After each of these runs, we analyze the maximum body size of the individual, size fluctuations, timing of spawning as well as total spawning output (number of eggs produced). We consider these life history traits to be indicative for the magnitude of "hardship" or "success" an individual experienced throughout its life.

In each of the environmental scenarios we perform model runs where the light- and temperature dependent scaling of krill metabolism is either switched on or off. When switched on, $M_{\text {reg }}\left(l_{D}, T\right)$ scales food uptake as well as somatic maintenance costs as described in section 2.7.3. When switched off the light- and temperature dependent scaling function $M_{\text {reg }}\left(l_{D}, T\right)$ is set to 1 which means that all physiological functions are running with their default parameterization. Thus, the "regulation off"-run acts as a control run. Consequently, differences in the model dynamics between "regulation off" and "regulation on" can be attributed to light- and temperature dependent scaling of krill metabolism.

\section{Results}

\subsection{Simulation experiment 1 - the impact of seasonal regulation of metabolism during low food winters}

When winter food is low (scenario "palmer"), krill reach maximum lengths of approximately $41 \mathrm{~mm}$ without and $46 \mathrm{~mm}$ with active metabolic scaling (Fig. 4a). The individuals reach the adult stage and therefore sexual maturity in their second year. After switching to the adult stage, the "regulated" and "unregulated" individuals start storing assimilates in their reproduction buffers but no spawning is triggered. With the onset of autumn and winter, these reserves are depleted in order to avoid starvation-induced shrinkage. However, after the full depletion of the energy reserves, the individuals start to reduce their size. This reduction is much stronger in the "unregulated" individual with size fluctuations of $16 \mathrm{~mm}$ compared to $10 \mathrm{~mm}$ in the "regulated" individual. The effect of the seasonal scaling function on the annual energy budget dynamics during the last simulation year are shown in Fig. 3.

Fig. 3 shows how the regulation of metabolism and feeding activity reduces the amplitude of starvation during the winter months. Without the metabolic regulation, the total winter energy deficit sums up to 99.5 $\mathrm{mg} \mathrm{C}$ whereas with metabolic regulation, the deficit equals $-81.3 \mathrm{mg} \mathrm{C}$. During the process of shrinkage, the "unregulated" individual repeatedly regresses to the juvenile stage. When food concentrations increase again, the individual starts to grow until it reaches the adult stage again. However, the amount of assimilates which are then allocated to reproduction never suffices to trigger a spawning event. In contrast, the "regulated" individual succeeds in spawning from its third summer on. Since the intra-annual size fluctuations are less pronounced, it does not regress into the juvenile stage and thus can store assimilates in the reproduction buffer as soon as spring sets in. The timing of the spawning is quite rhythmic with all three egg releases taking place in late February.

\subsection{Simulation experiment 2 - the impact of seasonal regulation of metabolism during high food winters}

When winter food concentrations are comparatively high (scenario: "palmer winter boost"), krill are able to reach larger sizes compared to the "palmer"-scenario from experiment 1 (Fig. 4b). The "regulated" and "unregulated" individuals grow to similar maximum sizes of 58 and 59 $\mathrm{mm}$ respectively after reaching the adult stage after 1 year. Individuals without seasonal metabolic scaling generally express higher growth rates and are generally larger compared to the "regulated" individual for the first 4 years. Therefore, individuals without metabolic scaling are able to reproduce earlier. Both individuals release eggs twice in their second summer - one year earlier than in the "palmer"-scenario. The distribution of spawning events is generally concentrated in December and January but isolated egg releases occur in spring (October) or autumn (March). The total reproductive output is slightly higher for "unregulated" individuals (22900 eggs) compared to "regulated" ones (21100 eggs).

In the third simulation year, the "unregulated" individual performs a spawning in late March which prevents it from building up sufficient energy reserves for the winter. As a consequence, starvation-induced shrinkage can be observed and the krill falls back to a slightly lower body length than the "regulated krill". When the "regulated" individual performs a late spawning in March in the $4^{\text {th }}$ simulation year, almost no shrinkage follows due to the reduced metabolic costs in winter. The size of both individuals starts to saturate in the $5^{\text {th }}$ year when structural maintenance costs become so high that all assimilates allocated to structure via the $\kappa$-branch need to be burned.

\section{Discussion}

As already demonstrated in Jager and Ravagnan (2015), the model is capable of producing plausible trajectories of growth, development and reproduction of individual krill. In this study, we advance the model with the addition of a seasonal component which scales krill metabolism as a function of light and temperature. The activation of seasonal metabolic scaling comes with distinct effects depending on the food availability during winter:

When food concentrations are high, decreasing metabolism slows down growth and ontogenetic development of krill since individuals cannot exploit the full energetic potential of the available food. This is consistent with feeding experiments carried out by Meyer et al. (2010) who exposed krill individuals to a similar range of food concentrations during winter and summer. In their results, winter feeding rates were up to six times lower than summer rates. As a consequence, individuals would not be able to make use of high food concentrations during winter. It is open for discussion whether this should be considered a disadvantage of seasonal metabolic scaling or a rare side-effect of an adaptation which is most beneficial in harsh winters. Generally, winter food availability in the Southern Ocean is low and patchily distributed (Meyer et al. 2017, Shen et al. 2017). In the Palmer time series which is used in this study, only $\sim 2 \%$ of the recorded chlorophyll a concentrations in June, July and August are higher than $0.25 \mathrm{mg} \mathrm{m}^{-3}(\mathrm{n}=509)$. Even though these data should not be interpreted as being representative of the entire habitat of krill, they emphasize the rareness of high concentrations of autotrophs during winter.

According to our simulations, seasonal scaling of metabolism decreases the amount of intra-annual shrinkage experienced when feeding conditions are less favorable. It is unclear whether lethal threshold values of shrinkage exist and whether a dampening might be lifesaving. In our simulations, annual size minima during winter in "unregulated" individuals correspond to $62 \%$ of the summer length or $24 \%$ of the summer structural biomass (dry weight) which is much lower than any reported weight losses (Auerswald et al. 2015; Ikeda and Dixon 1982). The activation of seasonal metabolic scaling reduces the intra-annual size fluctuations by half to $80 \%$ winter length compared to summer length. The simulated dry weight reduction of $\sim 50 \%$ compares to values on the upper end of non-lethal starvation-induced biomass losses reported from experiments and the field (Auerswald et al. 2015; Ikeda and Dixon 1982, Nicol et al. 1992). Consequently, light- and temperature driven scaling of metabolism might be a lifesaving adaptation which prevents potentially lethal starvation of krill during winter.

In addition, the down-regulation of metabolism is essential in order to allow successful reproduction in the subsequent summer in our model. In our simulations, it prevents annual regressions from the adult to the juvenile stage during winter. Remaining as an adult enables the krill to immediately invest energy into egg production once food concentrations increase in spring. Although the regression of the 
reproductive organs of adult krill to a juvenile appearance is possible (Thomas and Ikeda 1987), it remains questionable whether any individual could survive the drastic developmental alternation as experienced by the "unregulated" krill in the "palmer" scenario. The sexual regression described by Thomas and Ikeda (1987) was not accompanied by a reduction in body length much in contrast to our simulations.

However, and in general agreement with our model results, Cuzin-Roudy and Labat (1992) found adult individuals with juvenile ovaries in early summer in regions of the Weddell Sea with high sea-ice cover and low winter food concentrations. In contrast, individuals from regions in the Scotia Sea with higher winter productivity had either fully developed ovaries or had already spawned at the same time. According to our model, a possible reason for this might be the interaction of different winter food concentrations and seasonal regulation of metabolism.

In summary, the SERBIK model quantifies the role of temperatureand light dependent scaling of metabolism in krill. We investigate the effects of such scaling on the life history of krill under two environmental scenarios - one characterized by rather high winter food concentrations and one characterized by low winter food concentrations. Our results indicate that seasonal metabolic scaling could be essential for krill survival when winter food concentrations are low. On the other hand, it slows down the development of krill when winter food concentrations are high. However, the augmented winter food time series that we use to demonstrate this is at the upper end of observed winter values and is probably a rare case in the Southern Ocean where winter food availability is generally low. According to our model, seasonal scaling also plays a key role for successful reproduction of krill since saving energy during winter allows individuals to build up reproductive energy reserves faster at the onset of spring.

Most importantly, the model provides a first parameterization of the photo-regulation of metabolism in a mechanistic krill growth model. This makes the model especially applicable for spatial simulation experiments where individuals move through latitudinal gradients with different annual light regimes. In order to improve the model, future work should advance the reproduction submodel. The current concept of a threshold energy value oversimplifies the mechanisms of krill reproduction which has been described in more detail in Constable and Kawaguchi (2018) and Kawaguchi et al. (2007). Jager \& Ravagnan (2015) suggest an alternative reproduction function which forced individuals to reproduce after a fixed number of days. This leads to variable clutch sizes at each spawning which depend on the amount of assimilates stored in the reproduction buffer. However, this approach is detached from environmental drivers and as such may not be an improvement to the current method.

\section{Conclusion}

In conclusion, this study introduces and demonstrates the functioning of a bioenergetic krill growth model with special focus on the seasonal regulation of krill metabolism. This advancement is important for the investigation of krill responses to environmental fluctuations in the extremely seasonal habitat of the Southern Ocean. As demonstrated in this study, down-regulating foraging activity and metabolism during winter strongly changes the model predictions on krill life history, especially when food availability during winter is low. Because of its relative simplicity, the model is suitable for research which wants to scale from individuals to populations since it allows for many simulation runs while keeping computational efforts comparatively low. The application of such models will therefore advance the understanding of the krill life cycle in the critical over-wintering period which is an important goal for management strategies.

\section{CRediT authorship contribution statement}

Dominik Bahlburg: Conceptualization, Methodology, Software, Formal analysis, Validation, Writing - original draft, Writing - review \& editing, Visualization. Bettina Meyer: Conceptualization, Writing - review \& editing, Resources, Supervision, Funding acquisition. Uta Berger: Conceptualization, Writing - review \& editing, Supervision, Project administration, Funding acquisition.

\section{Declaration of Competing Interest}

The authors declare that they have no known competing financial interests or personal relationships that could have appeared to influence the work reported in this paper.

\section{Acknowledgement}

We thank Dr. Sally Thorpe (British Antarctic Survey) and Dr. Eugene Murphy (British Antarctic Survey) for valuable discussions and comments on the manuscript. We also thank the Long Term Ecological Research Network for the open access to environmental data from Palmer Station. This work was supported by the German Research Foundation (DFG, grant number 411096565). The model code is available under https://github.com/dbahlburg/SERBIK

\section{Supplementary materials}

Supplementary material associated with this article can be found, in the online version, at doi:10.1016/j.ecolmodel.2021.109427.

\section{References}

Atkinson, A., Meyer, B., Stuübing, D., Hagen, W., Schmidt, K., Bathmann, U.V., 2002. Feeding and energy budgets of antarctic krill euphausia superba at the onset of winter-II. Juveniles and Adults. Limnol. Oceanogr. 47 (4), 953-966. https://doi. org/10.4319/10.2002.47.4.0953.

Auerswald, Lutz, Meyer, Bettina, Teschke, Mathias, Hagen, Wilhelm, Kawaguchi, So, 2015. Physiological Response of Adult Antarctic Krill, Euphausia Superba, to LongTerm starvation. Polar Biol. 38 (6), 763-780. https://doi.org/10.1007/s00300-0141638-z.

Ballerini, Tosca, Hofmann, Eileen E., Ainley, David G., Daly, Kendra, Marrari, Marina, Ribic, Christine A., Smith, Walker O., Steele, John H., 2014. Productivity and linkages of the food web of the southern region of the western antarctic peninsula continental shelf. Prog. Oceanogr. 122, 10-29. https://doi.org/10.1016/j. pocean.2013.11.007. March.

Belcher, A., Tarling, G.A., Manno, C., Atkinson, A., Ward, P., Skaret, G., Fielding, S., Henson, S.A., Sanders, R., 2017. The Potential Role of Antarctic Krill Faecal Pellets in Efficient Carbon Export at the Marginal Ice Zone of the South Orkney Islands in Spring. Polar Biol. 40 (10), 2001-2013. https://doi.org/10.1007/s00300-017-2118-

Biscontin, Alberto, Wallach, Thomas, Sales, Gabriele, Grudziecki, Astrid, Janke, Leonard, Sartori, Elena, Bertolucci, Cristiano, et al., 2017. Functional characterization of the circadian clock in the Antarctic Krill. Euphausia Superba." Sci. Rep. 7 (1), 17742. https://doi.org/10.1038/s41598-017-18009-2.

Brown, Matthew, Kawaguchi, So, Candy, Steven, Virtue, Patti, 2010. Temperature effects on the growth and maturation of Antarctic Krill (Euphausia Superba). Deep Sea Res. Part II: Top. Stud. Oceanogr., Krill Biol. Ecol.: Dedic. Edward Brinton 1924-2010 57 (7), 672-682. https://doi.org/10.1016/j.dsr2.2009.10.016.

Brown, Matthew, Kawaguchi, So, Candy, Steven, Yoshida, Toshihiro, Virtue, Patti, Nicol, Steve, 2013. Long-term effect of photoperiod, temperature and feeding regimes on the respiration rates of Antarctic Krill (\&lt;I\&gt;Euphausia Superba\&lt;/ I\&gt;). Open J. Mar. Sci. 03 (02), 40-51. https://doi.org/10.4236/ ojms.2013.32A005.

Clarke, A., 2006. Temperature and the metabolic theory of ecology. Funct. Ecol. 20 (2), 405-412. https://doi.org/10.1111/j.1365-2435.2006.01109.x.

Constable, Andrew John, Kawaguchi, So, 2018. Modelling growth and reproduction of antarctic krill, euphausia superba, based on temperature, food and resource allocation amongst life history functions. ICES J. Mar. Sci. 75 (2), 738-750. https:// doi.org/10.1093/icesjms/fsx190.

Cuzin-Roudy, Janine, Labat, Jean Philippe, 1992. Early summer distribution of Antarctic Krill sexual development in the scotia-weddell region: a multivariate approach. Polar Biol. 12 (1), 65-74. https://doi.org/10.1007/BF00239966.

Einarsson, Baldvin, Birnir, Björn, Sigurðsson, Sven, 2011. A Dynamic Energy Budget (DEB) model for the energy usage and reproduction of the Icelandic Capelin (Mallotus Villosus). J. Theor. Biol. 281 (1), 1-8. https://doi.org/10.1016/j. jtbi.2011.03.031.

Gille, Sarah T., 2002. Warming of the Southern Ocean Since the 1950s. Science 295 (5558), 1275-1277. https://doi.org/10.1126/science.1065863.

Grimm, Volker, Berger, Uta, Bastiansen, Finn, Eliassen, Sigrunn, Ginot, Vincent, Giske, Jarl, Goss-Custard, John, Grand, Tamara, Heinz, Simone K., Huse, Geir, 2006. 
A standard protocol for describing individual-based and agent-based Models. Ecol. Modell. 198 (1-2), 115-126.

Grimm, Volker, Railsback, Steven F., Vincenot, Christian E., Berger, Uta, Gallagher, Cara, DeAngelis, Donald L., Edmonds, Bruce, et al., 2020. The ODD protocol for describing agent-based and other simulation models: a second update to improve clarity, replication, and structural realism. J. Artif. Soc. Soc. Simul. 23 (2), 7.

Groeneveld, Jürgen, Berger, Uta, Henschke, Natasha, Pakhomov, Evgeny A., Reiss, Christian S., Meyer, Bettina, 2020. Blooms of a key grazer in the Southern Ocean - an individual-based model of Salpa Thompsoni. Prog. Oceanogr. 185, 102339 https://doi.org/10.1016/j.pocean.2020.102339. June.

Guillaumot, Charlène, Saucède, Thomas, Morley, Simon A., Augustine, Starrlight, Danis, Bruno, Kooijman, Sebastiaan, 2020. Can DEB models infer metabolic differences between intertidal and subtidal morphotypes of the Antarctic Limpet Nacella Concinna (Strebel, 1908)?”. Ecol. Modell. 430, 109088 https://doi.org/ 10.1016/j.ecolmodel.2020.109088. August.

Hirche, Hans-Jürgen., 1984. Temperature and Metabolism of Plankton-I. Respiration of Antarctic Zooplankton at Different Temperatures with a Comparison of Antarctic and Nordic Krill. Comparat. Biochem. Physiol. Part A: Physiol. 77 (2), 361-368. https://doi.org/10.1016/0300-9629(84)90074-4.

Höring, Flavia, Teschke, Mathias, Suberg, Lavinia, Kawaguchi, So, Meyer, Bettina, 2018. Light regime affects the seasonal cycle of Antarctic Krill (Euphausia Superba): impacts on growth, feeding, lipid metabolism, and maturity. Can. J. Zool. 96 (11), 1203-1213. https://doi.org/10.1139/cjz-2017-0353.

Ikeda, T., 1984. Development of the Larvae of the Antarctic Krill (Euphausia Superba Dana) observed in the laboratory. J. Exp. Mar. Biol. Ecol. 75 (2), 107-117. https:// doi.org/10.1016/0022-0981(84)90175-8.

Ikeda, T., 1987. Mature Antarctic Krill (Euphausia Superba, Dana) grown from eggs in the laboratory. J. Plankton Res. 9 (3), 565-569. https://doi.org/10.1093/plankt/ 9.3.565.

Ikeda, T., Dixon, P., 1982. Body shrinkage as a possible over-wintering mechanism of the Antarctic Krill, Euphausia Superba Dana. J. Exp. Mar. Biol. Ecol. 62 (2), 143-151. https://doi.org/10.1016/0022-0981(82)90088-0.

Jager, Tjalling, Martin, Benjamin T., Zimmer, Elke I., 2013. DEBkiss or the Quest for the simplest generic model of animal life history. J. Theor. Biol. 328, 9-18. https://doi. org/10.1016/j.jtbi.2013.03.011. July.

Jager, Tjalling, Ravagnan, Elisa, 2015. Parameterising a Generic Model for the Dynamic Energy Budget of Antarctic Krill Euphausia Superba. Mar. Ecol. Prog. Ser. 519, 115-128. https://doi.org/10.3354/meps11098.

Jia, Zhongnan, Virtue, Patti, Swadling, Kerrie M., Kawaguchi, So, 2014. A photographic documentation of the development of Antarctic Krill (Euphausia Superba) from egg to early juvenile. Polar Biol. 37 (2), 165-179. https://doi.org/10.1007/s00300-0131420-7.

Kawaguchi, Kouichi, Shingo Ishikawa, and Osamu Matsuda. 1986. "The Overwintering Strategy of Antarctic Krill (Euphausia Superba DANA) under the coastal fast ice of the Ongul Islands in Lutzow-Holm Bay, Antarctica." In.

Kawaguchi, S., 2016. Reproduction and Larval Development in Antarctic Krill (Euphausia Superba).”. Biology and Ecology of Antarctic Krill. Springer Berlin Heidelberg, New York, NY.

Kawaguchi, So, Yoshida, Toshihiro, Finley, Luke, Cramp, Paul, Nicol, Stephen, 2007. The Krill Maturity Cycle: a conceptual model of the seasonal cycle in Antarctic Krill. Polar Biology 30 (6), 689-698. https://doi.org/10.1007/s00300-006-0226-2.

Kooijman, S.A.L.M, 2010. Dynamic Energy Budget Theory for Metabolic Organisation. Cambridge university press.

Le Fèvre, Jacques, Legendre, Louis, Rivkin, Richard B., 1998. Fluxes of Biogenic Carbon in the Southern Ocean: Roles of Large Microphagous Zooplankton1Contribution to Programme Antares (JGOFS-France), and to the Programmes of GIROQ (Groupe Interuniversitaire de Recherches Océanographiques Du Québec) and the Ocean Sciences Centre. Mem. Univ. Newfoundland.1.” J. Mar. Syst. 17 (1), 325-345. https://doi.org/10.1016/S0924-7963(98)00047-5.

Llandres, Ana L., Marques, Gonçalo M., Maino, James L., a. L. M. Kooijman, S., Kearney, Michael R., Casas, Jérôme, 2015. A dynamic energy budget for the whole life-cycle of holometabolous insects. Ecol. Monogr. 85 (3), 353-371. https://doi.org/ 10.1890/14-0976.1.

Martin, Benjamin T., Jager, Tjalling, Nisbet, Roger M., Preuss, Thomas G., Grimm, Volker, 2013. Predicting population dynamics from the properties of individuals: a cross-level test of dynamic energy budget theory. Am. Nat. 181 (4), 506-519. https://doi.org/10.1086/669904.

edited by McWhinnie, M.A., Marciniak, P., 1964. Temperature responses and tissue respiration in Antarctic Crustacea with Particular Reference to the Krill Euphausia Superba. In: Lee, Milton O (Ed.), Antarctic Research Series. American Geophysical Union, Washington, D.C, pp. 63-72. https://doi.org/10.1029/AR001p0063. edited by.

Meyer, Bettina, Auerswald, Lutz, Spahic, Susanne, Pape, Carsten, Teschke, Mathias, Fach, Bettina, Lopata, Andreas, Fuentes, Veronica, 2010. Seasonal variation in body composition, metabolic activity, feeding, and growth of adult krill euphausia superba in the Lazarev Sea. Mar. Ecol. Prog. Ser. 398. https://doi.org/10.3354/ meps08371. January.

Meyer, Bettina, Freier, Ulrich, Grimm, Volker, Groeneveld, Jürgen, Hunt, Brian P.V., Kerwath, Sven, King, Rob, et al., 2017. The winter pack-ice zone provides a sheltered but food-poor habitat for Larval Antarctic Krill. Nat. Ecol. Evol. 1 (12), 1853-1861. https://doi.org/10.1038/s41559-017-0368-3.

Morris, Max D., 1991. Factorial sampling plans for preliminary computational experiments. Technometrics 33 (2), 161-174. https://doi.org/10.1080/ 00401706.1991.10484804.

Ngan, Phan Van, Gomes, Vicente, Carvalho, Paulo S.M., Passos, Maria José de A.C.R., 1997. Effect of body size, temperature and starvation on oxygen consumption of Antarctic Krill Euphausia Superba. Rev. Bras. Oceangr. 45 (1-2), 01-10. https://doi. org/10.1590/S1413-77391997000100001.

Nicol, S, Stolp, M, Cochran, T, Geijsel, P, Marshall, J, 1992. Growth and Shrinkage of antarctic krill euphausia superba from the Indian Ocean Sector of the Southern Ocean during summer. Mar. Ecol. Prog. Ser. 89, 175-181. https://doi.org/10.3354/ meps089175.

Nicol, Stephen., 1990. The age-old problem of krill longevity. Bioscience 40 (11), 833-836. https://doi.org/10.2307/1311486.

Piccolin, Fabio, Meyer, Bettina, Biscontin, Alberto, De Pittà, Cristiano, Kawaguchi, So, Teschke, Mathias, 2018a. Photoperiodic Modulation of Circadian Functions in Antarctic Krill Euphausia Superba Dana, 1850 (Euphausiacea). J. Crustac. Biol. 38 (6), 707-715. https://doi.org/10.1093/jcbiol/ruy035.

Piccolin, Fabio, Suberg, Lavinia, King, Robert, Kawaguchi, So, Meyer, Bettina, Teschke, Mathias, 2018b. The Seasonal Metabolic Activity Cycle of Antarctic Krill (Euphausia Superba): evidence for a role of photoperiod in the regulation of endogenous rhythmicity. Frontiers in Physiology 9. https://doi.org/10.3389/ fphys.2018.01715. December.

edited by Quetin, L.B., Ross, R.M., Clarke, A., El-Sayed, S.Z., 1994. Krill energetics: seasonal and environmental aspects of the physiology of euphausia superba. Southern Ocean Ecology: The BIOMASS Perspective. Cambridge University Press, Cambridge, pp. 165-184. edited by. http://nora.nerc.ac.uk/id/eprint/517322/.

R Core Team. 2020. R: A Language and Environment for Statistical Computing. R Foundation for Statistical Computing. Vienna, Austria. https://www.R-project.org/.

Ren, Jeffrey S., Ross, Alex H., 2001. A dynamic energy budget model of the pacific oyster crassostrea gigas. Ecol. Modell. 142 (1), 105-120. https://doi.org/10.1016/S03043800(01)00282-4.

Seear, Paul, Tarling, Geraint, Goodall-Copestake, Will, Fleming, A.H., Rosato, Ezio, 2012. Seasonal and spatial influences on gene expression in Antarctic Krill (Euphausia Superba Dana). Mar. Ecol. Prog. Ser. 467, 61-75. https://doi.org/10.3354/ meps09947. October.

Segawa, S., Kato, M., Murano, M, 1979. Oxygen consumption of the Antarctic Krill. Trans. Tokyo Univ. Fish. 3, 113-119.

Shen, Yuan, Benner, Ronald, Murray, Alison E., Gimpel, Carla, Mitchell, B.Greg, Weiss, Elliot L., Reiss, Christian, 2017. Bioavailable dissolved organic matter and biological hot spots during Austral Winter in Antarctic Waters. J. Geophys. Res.: Oceans 122 (1), 508-520. https://doi.org/10.1002/2016JC012301.

Siegel, V., Loeb, V., 1994. Length and age at maturity of Antarctic Krill. Antarct. Sci. 6 (4), 479-482. https://doi.org/10.1017/S0954102094000726.

edited by Smith, Raymond C., Fraser, William R., Stammerjohn, Sharon E., Vernet, Maria, 2013. Palmer long-term ecological research on the Antarctic Marine ecosystem. In: Domack, Eugen, Levente, Amy, Burnet, Adam, Bindschadler, Robert, Convey, Pete, Kirby, Matthew (Eds.), Antarctic Research Series. American Geophysical Union, Washington, D. C., pp. 131-144. https://doi.org/10.1029/ AR079p0131. edited by.

Sousa, Tânia, Domingos, Tiago, Poggiale, J.-C., Kooijman, S.A.L.M, 2010. Dynamic energy budget theory restores coherence in biology. Philos. Trans. R. Soc. B: Biol. Sci. 365 (1557), 3413-3428. https://doi.org/10.1098/rstb.2010.0166.

Tarling, Ga, Cuzin-Roudy, J, Thorpe, Se, Shreeve, Rs, Ward, P, Murphy, Ej, 2007. Recruitment of Antarctic Krill euphausia superba in the south georgia region: adult fecundity and the fate of Larvae. Mar. Ecol. Prog. Ser. 331, 161-179. https://doi. org/10.3354/meps331161. February.

Tarling, Geraint A., 2020. Routine Metabolism of Antarctic Krill (Euphausia Superba) in South Georgia Waters: Absence of Metabolic Compensation at Its Range Edge. Mar. Biol. 167 (8), 108. https://doi.org/10.1007/s00227-020-03714-w.

Teschke, Mathias, Kawaguchi, So, Meyer, Bettina, 2007. Simulated light regimes affect feeding and metabolism of Antarctic Krill, Euphausia Superba. Limnol. Oceanogr. 52 (3), 1046-1054. https://doi.org/10.4319/10.2007.52.3.1046.

Thieurmel, Benoit, and Achraf Elmarhraoui. 2019. Suncalc: compute sun position, sunlight phases, moon position and lunar phase (version $\mathrm{R}$ package version 0.5.0.). https://CRAN.R-project.org/package=suncalc.

Thomas, P.G., Ikeda, T., 1987. Sexual regression, shrinkage, re-maturation and growth of spent female euphausia superba in the laboratory. Mar. Biol. 95 (3), 357-363. https://doi.org/10.1007/BF00409565.

Whitehouse, M.J., Meredith, M.P., Rothery, P., Atkinson, A., Ward, P., Korb, R.E., 2008. Rapid warming of the ocean around South Georgia, Southern Ocean, during the 20th Century: forcings, characteristics and implications for lower trophic levels. Deep Sea Res. Part I 55 (10), 1218-1228. https://doi.org/10.1016/j.dsr.2008.06.002.

Wickham, Hadley, Averick, Mara, Bryan, Jennifer, Chang, Winston, McGowan, Lucy, François, Romain, Grolemund, Garrett, et al., 2019. Welcome to the Tidyverse. J. Open Source Softw. 4 (43), 1686. https://doi.org/10.21105/joss.01686. 